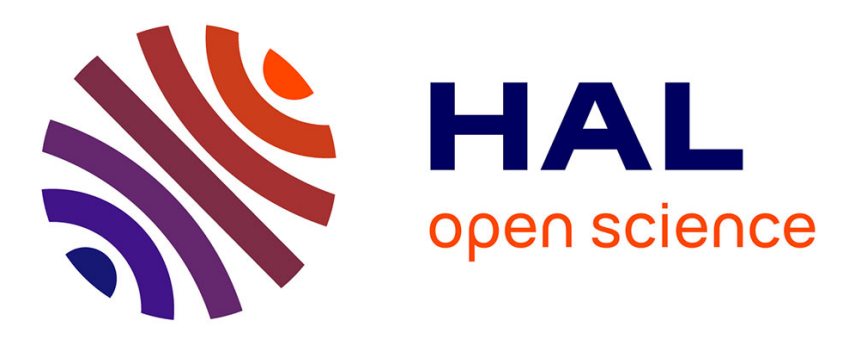

\title{
Determination of sea bottom characteristics using acoustic field space dependence
}

\author{
M. Fokina, V. Fokin, B. Kerzhakov
}

\section{To cite this version:}

M. Fokina, V. Fokin, B. Kerzhakov. Determination of sea bottom characteristics using acoustic field space dependence. Journal de Physique IV Proceedings, 1994, 04 (C5), pp.C7-1091-C7-1094. 10.1051/jp4:19945240 . jpa-00252928

\section{HAL Id: jpa-00252928 https://hal.science/jpa-00252928}

Submitted on 1 Jan 1994

HAL is a multi-disciplinary open access archive for the deposit and dissemination of scientific research documents, whether they are published or not. The documents may come from teaching and research institutions in France or abroad, or from public or private research centers.
L'archive ouverte pluridisciplinaire HAL, est destinée au dépôt et à la diffusion de documents scientifiques de niveau recherche, publiés ou non, émanant des établissements d'enseignement et de recherche français ou étrangers, des laboratoires publics ou privés. 


\title{
Determination of sea bottom characteristics using acoustic field space dependence
}

\author{
M.S. FOKINA, V.N. FOKIN and B.V. KERZHAKOV
}

Institute of Applied Physics, Russian Academy of Sciences, 46 Ulyanov St., 603600 Nizhny Novgorod, Russia

\begin{abstract}
The effect of the layer structure of the elastic absorbing bottom on the space-frequency dependences of acoustic fields in shallow and deep seas in the frequency range $20-500 \mathrm{~Hz}$ is studied. The comparison of the experimental losses due to sound propagation in the deep-water part of the Atlantic Ocean at three frequencies and the results of numerical calculations by ray programs has shown that the experimental and calculated losses may agree satisfactory only if the layer bottom structure is taken into account. The numerical study in the frames of the approximation of adiabatic modes has shown that an absorbing layer of the geological bottom structure of the Barents Sea influences significantly the characteristics of sound fields and enriches the field mode spectrum. It is shown that the degree of this effect depends on the seasonal fluctuations of the sound velocity profile structure. The relation between the type of sediments which form bottom layers and frequency ranges, where the least losses due to propagation are observed, i.e. optimum propagation frequencies, is ascertained.
\end{abstract}

\section{INTRODUCTION}

In the frames of mathematical physics a deterministic ocean presents a liquid layer covering an elastic stratified medium. Methods of the bottom account are elaborated in different approaches to take into account the bottom structure. In particular, in the article [1] a numerical treatment of the horizontal liquid/elastic interface boundary are introduced. It is known that the stratification effect on the acoustic field characteristics is essential and can be compared with the effect of the waveguide sound propagation. The numerical modeling ocean - bottom reflection loss using the plane - wave reflection coefficient calculated for the bottom model consist of fluid sediment layers overlying an elastic substrate are introduced in the paper [2].

The mathematical problem of determining the interference coefficients of sound reflection from the set of layers covering the substrate are solved by matrix methods. To determine the modulus and the phase for coefficients of the plane wave reflection at the bottom, the technique of matrix propagator (suggested in $[3,4]$ and developed in [5]) was numerically realized. Using the method of matrix propagator we get the set of equations for finding coefficients of the reflected waves $V$ and the factors of the penetration of longitudinal and transverse waves $W_{\ell, t}$ from the system of the arbitrary number of elastic (liquid) layers:

$$
\begin{gathered}
W_{t}=-W_{l} q_{7} / q_{8}, \\
V=1+W_{l} q_{3} / i d_{0}-W_{l} q_{7} q_{4} / q_{8} i \alpha_{0}, \\
W_{l}=2 /\left(-q_{5} / \omega^{2} \rho_{0}+q_{7} q_{6} / q_{8} \omega^{2} \rho_{0}-q_{3} / i \alpha_{0}+q_{7} q_{4} / q_{8} i \alpha_{0}\right) .
\end{gathered}
$$




$$
\begin{aligned}
& q_{1}=a_{11} i \xi-a_{12} i \alpha_{1}+a_{13} 2 \mu_{1} \xi \gamma_{1}+a_{14} 2 \mu_{1} \xi \alpha_{1}, \\
& q_{2}=a_{11} i \beta_{1}+a_{12} i \xi+a_{13} 2 \mu_{1} \xi \beta_{1}-a_{14} 2 \mu_{1} \xi \gamma_{1}, \\
& q_{3}=a_{21} i \xi-a_{22} i \alpha_{1}+a_{23} 2 \mu_{1} \gamma_{1}+a_{24} 2 \mu_{1} \xi \beta_{1}, \\
& q_{4}=a_{21} i \beta_{1}+a_{22} i \xi+a_{23} 2 \mu_{1} \xi \beta_{1}-a 242 \mu_{1} \xi \gamma_{1}, \\
& q_{5}=a_{31} i \xi-a_{32} i \alpha_{1}+a_{33} 2 \mu_{1} \xi \gamma_{1}+a_{34} 2 \mu_{1} \xi \alpha_{1}, \\
& q_{6}=a_{31} i \beta_{1}+a_{32} i \xi+a_{33} 2 \mu_{1} \xi \beta_{1}-a_{34} 2 \mu_{1} \xi \gamma_{1}, \\
& q_{7}=a_{41} i \xi-a_{42} i \alpha_{1}+a_{43} 2 \mu_{1} \xi \gamma_{1}+a_{44} 2 \mu_{1} \xi \alpha_{1}, \\
& q_{8}=a_{41} i \beta_{1}+a_{42} i \xi+a_{43} 2 \mu_{1} \xi \beta_{1}-a_{44} 2 \mu_{1} \xi \gamma_{1},
\end{aligned}
$$

where the values, belonging to water and elastic half-spaces have index 0 and $1, a_{i j}$ are the elements of matrix propagator $\hat{A}$.

\section{NUMERICAL TREATMENT}

The mathematical analysis of the reflection loss dependences in Eq.(2) being rather complex, let us numerically estimate $V(\theta)$ and consider the changes in this dependence with the variations of one of the layered bottom parameters. Such consideration allows to determine some regularities in $V(\theta)$ behavior and to qualitatively estimate the expected field level.

The calculations were made by ray program [6] using a waveguide with an even layered bottom which was homogeneous along the trace. The effect of the bottom in this model is rather strong. Figure 1 gives the results of calculations for the modulus and the phase of the reflection coefficient at the bottom $(|V|, \arg V)$ and losses in $d B$ per $1 k m \beta=(1-|V(\theta)|)^{2} / D\left(x_{L}\right)$, where $D\left(x_{L}\right)$ is the length of the ray circuit, as a function of the grazing angle near the bottom for frequency $400 \mathrm{~Hz}$, the thickness of the first and the second sedimentary layer being $d_{1}=0,1,2,3,4,5 m, d_{2}=2 d_{1}$.
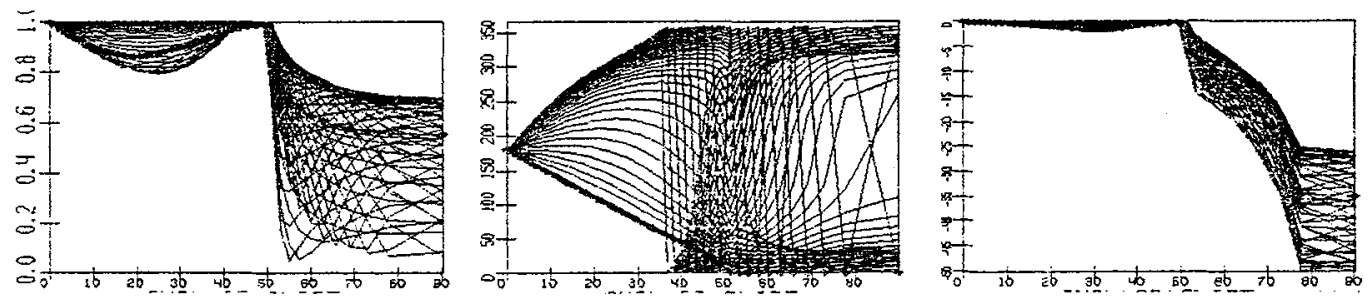

Fig.1 Dependences $V(\theta)$, when the thickness of the sedimentary layer vary $d=0 \div 100 \mathrm{~m}$ : a - the modulus $|V(\theta)|$ and $\mathrm{b}$ - the phase $\arg V(\theta)$ of the reflection coefficient at the layered bottom; c-losses in $d B$ per $1 \mathrm{~km} \beta(\theta)$ as a functions of the grazing angle.

The curves corresponding to the signal reflection at an elastic half-space $d_{1}=d_{2}=0 \mathrm{~m}$ are shown by markers. It is evident from Fig. 1 that the introduction of the sedimentary layer and the growth of its thickness up to $d=70 \mathrm{~m}$ result in the increase of losses during the propagation for all angles (except $\theta_{c} \approx 50^{\circ}$ ). When the sedimentary layer reaches the thickness $70 \mathrm{~m}$, the character of $V(\theta)$ dependence changes and the modulus $|V(\theta)|$ begins to increase. This is the evidence that the optimum propagation frequency may appear connected with the sediment layer availability. The influence of the sediment layer on the $V(\theta)$ decreases if the frequency decreases. The similar dependences $|V(\theta)|$ can be plotted when other parameters in the sedimentary layer vary (such as the longitudinal sound speed $c_{\ell_{1}}$ ), the sedimentary layer density $\left.\rho_{1}\right)$. The dependence $V(\theta)$ doesn't essentially change in this case. 
The influence of the parameters of the elastic half-space (the longitudinal and transverse sound speed $\left.c_{\ell 2}, c_{t 2}\right)$ on $|V(\theta)|$ is more essential. If we take into account transverse waves in the elastic half-space, then the total inner reflection disappears and $\mid V(\theta)$ decreases at small grazing angles. If $c_{t 2}$ increases to the value more than $c_{\ell 1}$ in to the layer, there appears an interval of the angles on the plotted dependence $|V(\theta)|$, where $|V(\theta)|=1$. In the shallow water smaller angles correspond to lower numbers modes, i.e. the increase of $c_{t}$ results in the increasing sound damping at low frequencies that (alongside with high-frequency damping due to volume absorbtion) produces prerequisites for the appearance of the optimal propagation frequency.

To determine how the sound speed profile in the waveguide affects the acoustic field level we calculated the acoustic field for various seasonal conditions of propagation. The analysis of the calculations made us to conclude that in summer sound propagation strongly depends on the sea bottom characteristics due to rays negative refraction (downwards). In winter the influence of the sea bottom decreases due to positive rays refraction (upwards).

Consider the effect of the sediment composition on the acoustic field level. Figure $2, a, b$ gives the isolines of the acoustic field in a frequency range $20-200 \mathrm{~Hz}$ for two types of sediments: layer of sand silt (Fig.2, $a$ ) and layer of silt, clay (Fig.2,b), situated on an elastic half - space filled with silty sand.
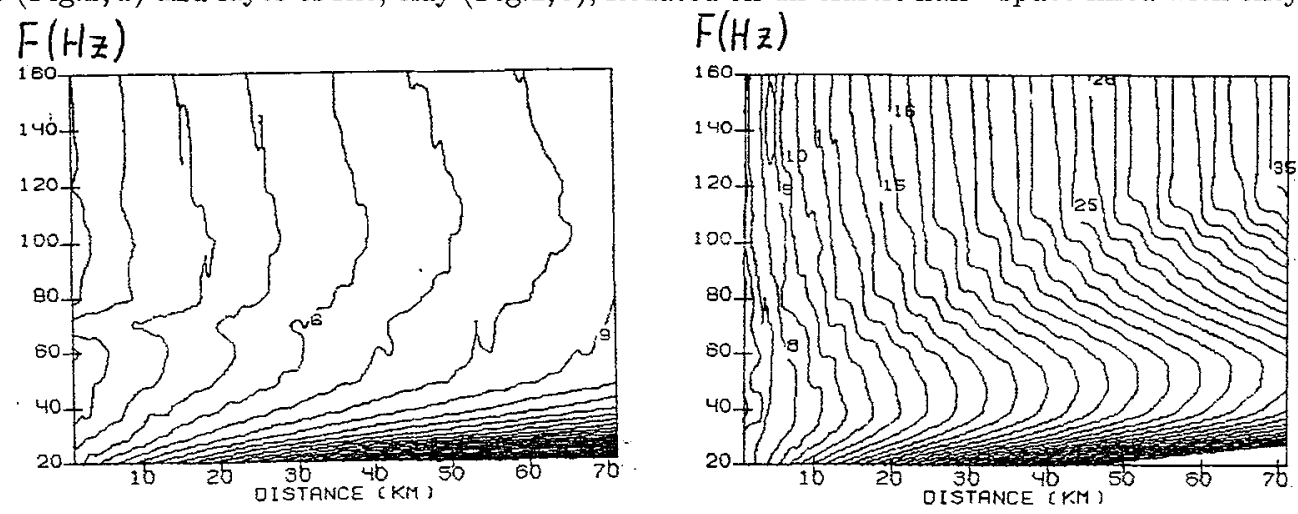

Fig.2 Isolines of the acoustic field intensity on the plane - distance-frequency for to two types of sediments: a - layer of sand silt ; b-layer of silt, clay, situated on an elastic half-space filled with silty sand.

The profile of sound speed corresponded to the summer period. The correlation of both the acoustic field level and the optimal signal propagation frequency with the sediment properties is evident.

\section{BOTTOM PARAMETERS RECONSTRUCTION}

This paper shows the possibility to determine bottom characteristics based on direct acoustic field measurements and on the analysis of the above regularities of the $V(\theta)$ angular dependence behavior. Here we used the experimental data obtained during the expedition in the deep part of Atlantic Ocean.

Preliminary estimations of the number of layers and their parameters were made by analyzing the experimental dependences of the acoustic fields for the three frequencies 33,237 and $533 \mathrm{~Hz}$ (see Fig.3,a).

The plots representing the acoustic field show that at grazing angles $\theta_{c}=25^{\circ}-30^{\circ}$ at the distance $20 \mathrm{~km}$ the field decreases at all the frequencies that can be explained by total inner reflection. The sound speed in the layer corresponding to this critical angle is $c_{2}=c_{b} / \cos \theta_{c 2}=1770 \mathrm{~m} / \mathrm{s}$, where $c_{b}$ is the sound speed in the water near the bottom. At low frequencies of 133 and $237 \mathrm{~Hz}$ the observed field 
jump at the distance $4 k m$ at grazing angles $\theta_{c 1}=60^{\circ}-75^{\circ}$ is, probably, associated with the interaction of the low - frequency sound with deeper layers with the speed $c_{\ell 1}=c_{b} / \cos \theta_{c 1}=3000-3500 \mathrm{~m} / \mathrm{s}$. Besides, we see the field increase at the distance $22-30 \mathrm{~km}$ at small grazing angles $\theta<\theta_{c 2}$. The value of this decrease is characterized by a pronounced frequency dependence: the level of field decreases with the decrease of frequency and is practically absent at $f=133 \mathrm{~Hz}$ at the distance $22-30 \mathrm{~km}$. It can be connected with the presence of a fine near-surface liquid layer having the sound speed smaller than that in water and characterized by a more rigid substrate. The maximum effect of this layer being observed at a high frequency, we shall consider the behavior of the field at the frequency $f=533 \mathrm{~Hz}$ when determining the layer parameters. The analysis showed that we can suggest the next 2-layer model of sediments placed on an elastic half-space:
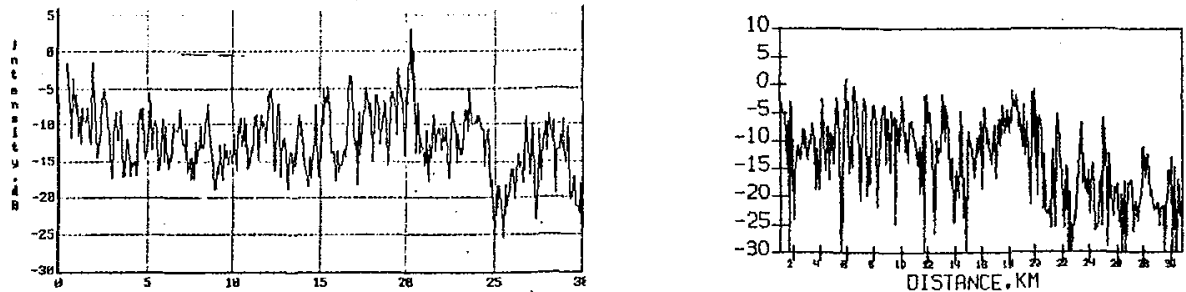

Fig.3 Dependences of acoustic field from the distance: a - the experimental dependence and $\mathrm{b}$ - the calculation dependence for the frequency $F=533 \mathrm{~Hz}$.

1-st liquid layer: $c_{\ell 1}<c_{b}=1539 \mathrm{~m} / \mathrm{s}$,

2-nd liquid layer: $c_{\ell 2}=1770 \mathrm{~m} / \mathrm{s}$,

elastic half-space: $c_{\ell}=3500 \mathrm{~m} / \mathrm{s}$.

To make "slight" correction of the bottom parameters, the results of numerical simulation carried out according to the ray program were "fit" to be in good agreement with the experimental data. Figure $3, b$ gives calculation results of the acoustic field for the frequency $F^{\prime}=533 \mathrm{~Hz}$.

\section{CONCLUSION}

The regularities in the behavior of the module and phase of the coefficient of reflection by an elastic layered sea bottom are considered. The influence of a layer sea bottom on the propagation of sound fields in inhomogeneous ocean waveguides is studied. The relation between the types of sedimentary layers in the Barents Sea and the frequency ranges, where the least losses are observed, i.e. the optimum propagation frequencies, are ascertained.

Based on the peculiarities revealed in the behavior of the angular dependence of the reflection coefficient, the layered bottom structure and its geoacoustic characteristics are restored using the experimental data.

\section{References.}

[1] Er-Chang Shang and Ding Lee, JASA 85 (1989) 654-660.

[2] N. Ross Chapman, JASA 73 (1983) 1601-1607.

[3] Thomson W.T., J. Appl. Phys. 21 (1950) 89-93.

[4] Haskell N.A., Bull. Seismol. Soc. Amer. 43 (1953) 17-34.

[5] Brekhovskikh L.M. and Godin O.A., Acoustics of Stratified Media (1989) p.p.100-104.

[6] Fokin V.N. and Fokina M.S., Akust. Zh. 37 (1991) 782-788. 